\title{
Association between Oral Health and Body Mass Index among Schoolchildren
}

\author{
Fehim Haliti ${ }^{1}$, Ardiana Murtezani ${ }^{2}$, Bernard Tahirbegolli ${ }^{3}$, Dafina Dobërdoli ${ }^{4}$, Arbnore Batalli-Këpuska ${ }^{5}$
}

\begin{abstract}
Aim and objective: This study aimed to investigate the association of oral health by body mass index (BMI) among schoolchildren of Kosovo. Materials and methods: A comparative-descriptive study was conducted using a sample of 270 children of age group 12-14 years, of both genders, who were selected from various schools along with Kosovo. A questionnaire was used to obtain information on children's demographic characteristics, oral hygiene practices, and dietary habits. Their parental education levels, family incomes, and leisure time activities were also obtained by questionnaire at recruitment. Clinical outcomes were assessed according to the Decayed/Missing/Filled Teeth (DMFT) index and the oral hygiene index-simplified (OHI-S). Adjusted for age, gender, height, and weight, BMI-age percentiles were calculated using the BMI Percentile Calculator for Child and Teen, and children were classified as underweight, normal, overweight, and obese considering age and sex. In the statistical analysis, differences between categorical variables were tested with the Chi-square test $\left(\chi^{2}\right)$ and contingency tables.

Results: Caries was present in $47.4 \%$ of children. A maximum number of caries affected children belonged to the healthy weight and obesity group, followed by overweight, and the least number was underweight $(p<0.003)$. We found a significant difference between DMFT ( $p<0.02)$ and $\mathrm{OHI}-\mathrm{S}$ values $(p<0.002)$ and BMI-age percentiles subgroups.

Conclusion: The results show a difference in outcomes between DMFT and OHI-S values among BMI-age percentiles subgroups in schoolchildren. Children aged 12 years, from the obese category, had more cases with higher DMFT (significant difference $p<0.003$ ), and also more cases with the high OHI-S value were detected among children from the obesity subgroup $(p<0.002)$.

Clinical significance: Obesity, oral health, and dental caries have common risk determinants and require a comprehensive multidisciplinary approach to children by both medical and dental healthcare professionals.

Keywords: Caries, Obesity, Oral health, Physical activity, Schoolchildren.

World Journal of Dentistry (2021): 10.5005/jp-journals-10015-1781
\end{abstract}

\section{INTRODUCTION}

Obesity is chronic, global epidemic disease, increasing in many countries around the world. ${ }^{1}$ It is mainly caused by regularly consuming more calories from food and drink than the body uses, and low physical activity. ${ }^{2}$ Staying on the smartphone, using a computer, and playing video games take a lot of leisure time away from children, avoiding their physical activity. This lifestyle expends little energy, and during this time, children consume highcalorie foods and drinks, ${ }^{3}$ and these are the main causes of being overweight or obese. ${ }^{4}$

There is a piece of evidence supporting an association between overweight and oral health in children. ${ }^{5}$ Many scientific studies have revealed a high level of dental caries and gingival inflammation in overweight and obese children. ${ }^{6}$ Dental caries is the most prevalent oral disease and is the main dental public health problem in schoolchildren. ${ }^{7}$ Dental caries may be depending on oral hygiene, fluoride intake, cariogenic diet, lifestyle factor, and host factors (salivary flow, buffer capacity, and buccal microflora), ${ }^{8}$ presence of abnormalities or enamel defects. ${ }^{9}$

Except for these factors, low income, low socioeconomic status, low level of parents' education, are also risk factors for periodontal disease and caries. ${ }^{10}$

However, there have been little researches in Kosovo assessing oral health, the prevalence of dental caries, lifestyle factors in relation to obesity. This cross-sectional study was designed to assess the prevalence of dental caries and oral health in relation to obesity in 12- to 14-year-old children attending public schools in Kosovo.
${ }^{1}$ Department of Pediatric Dentistry, School of Dentistry, Faculty of Medicine, University "Hasan Pristina", Republic of Kosovo

${ }^{2,4}$ Department of Physical and Rehabilitation Medicine, University Clinical Center of Kosovo, Pristina, Republic of Kosovo

${ }^{3}$ Department of Health Institutions and Services, Heimerer College Pristina, Kosova

${ }^{5}$ Department of Pediatrics, University Clinical Center of Kosovo, Pristina, Republic of Kosovo

Corresponding Author: Arbnore Batalli-Këpuska, Department of Pediatrics, University Clinical Center of Kosovo, Pristina, Republic of Kosovo, Phone: +38344207268, e-mail: abkepuska@gmail.com

How to cite this article: Haliti F, Murtezani A, Tahirbegolli B, et al. Association between Oral Health and Body Mass Index among Schoolchildren. World J Dent 2021;12(1):84-88.

Source of support: Nil

Conflict of interest: None

The objective of this study was to investigate the relationship between dental caries, oral health by body mass index (BMI) among schoolchildren of Kosovo.

\section{Materials and Methods}

\section{Subject's Enrollment}

This cross-sectional study was conducted in Kosovo. Three public elementary schools from three municipalities were randomly 
selected. Ethical approval for the study was obtained from the Ethics Committee of the University of Prishtina. Children with obvious diseases or physical, mental deformities, diabetes mellitus, or other systemic illnesses were excluded from the sample. The children/parents who were not willing to participate were excluded also. Children aged 12-14 years from those schools were invited to participate in this study. Among 1,620 children, 270 (16.6\%) were recruited, and written informed consent was obtained from the parents of all children who participated in the study. The recruitment took place between January 2019 and March 2019, and the data collection was conducted between April 2019 and July 2019. Finally, 270 (128 girls and 142 boys) pre-adolescents were included in this study.

The data collection consisted of three parts: a dental examination, anthropometric assessments (measuring body height and weight), and completion of a questionnaire.

\section{Questionnaire}

A standardized questionnaire was administered to the parents/ guardians and was used to determine information on the following: children's demographic and socioeconomic characteristics (their parental education levels, family incomes), children's oral health practices (i.e., toothbrushing frequency; use of fluoride paste, child's last dental visit), dietary habits (nutritional cariogenic intake), and physical activities of the subjects. Children who exercised at least three times a week for more than 1 hour regularly, were considered to be physically active.

The questionnaire included nine questions in the open/close form, three of which required only "yes or no" answers, and six optional questions inviting longer answers.

\section{Anthropometric Assessments}

Adjusted for age, gender, height, and weight BMI-age percentiles were calculated using the BMI Percentile Calculator for Child and Teen based on the Centers for Disease Control (CDC) growth charts for children and teens (https://www.cdc.gov/healthyweight/bmi/ calculator.html). The children, wearing school uniforms, were weighed and had their height measured in bare feet, on a standard balance beam scale. Children were classified into four categories using age- and gender-specific criteria recommended by the CDC: ${ }^{11}$ underweight-less than 5th percentile; normal weight-5th percentile to less than 85 th percentile; at risk of overweight -85 th to less than 95 th percentile.

\section{Dental Examination}

The oral examinations were conducted by a single examiner under natural light with dental instruments, seated in a regular school chair. Dental caries assessments were carried out using criteria recommended by the World Health Organization (WHO). ${ }^{12}$ The Decayed, Missing and Filled Teeth (DMFT) index was used to record the caries status of the permanent dentition. Debris and calculus were assessed by oral hygiene index-simplified (OHI-S) according to Green and Vermillion. ${ }^{13}$

The data were collected by a trained researcher.

\section{Statistical Analysis}

The categorical variables were summarized as frequency $(n)$ and percentages (\%). In the statistical analysis, differences between categorical variables were tested with the chi-square test $\left(\chi^{2}\right)$ and contingency tables. All statistical analyzes were performed using the Statistical Package for Social Science SPSS 22.0. Statistical significance was established at the $p<0.05$ level.

\section{Results}

A total of 270 schoolchildren (142 male and 128 female) aged 12-14 years of both genders, selected randomly from different schools along Kosovo were part of the study. Ninety-one were children aged 12 years, 87 aged 13 years, and 92 aged 14 years. Table 1 shows the distribution by gender, age, income, parental education, and regular physical activity within the sample. Also, the prevalence of some characteristics of the study population related to oral health are shown in Table 1, like a visit to a dentist, teeth brushing, sweet eating habits, using fluoride paste, caries, DMFT, BMI-age percentiles, and $\mathrm{OHI}$. In addition, there were no significant differences between the groups in the variable rates, such as gender, age, visits to the dentist, teeth brushing, caries, and regular physical activity $(p>$ 0.05), except for family income, parental education, using fluoride paste, sweet eating habits, BMI-age percentiles, DMFT, and $\mathrm{OHI}$ score $(p<0.001)$ (Table 1$)$.

Table 2 provides the prevalence of DMFT value in each BMI-age percentile subgroup, based on age. Children aged 12 years, from the obese category (40\%), had more cases with higher DMFT compared to other categories (significant difference $p<0.003$ ), while children aged 13 years and 14 years, from the category of children with normal weight, had more cases with higher DMFT (48\%, respectively, $43.8 \%$ ) compared to other categories, but without significant difference ( $p<0.217$, respectively, 0.382 ).

The DMFT value prevalence of children according to BMI subgroup are shown in Table 3. We found a significant difference ( $p$ $<0.02$ ) between DMFT values and BMI-age percentiles subgroups. In the groups including healthy (43.1\%) and obese (36.1\%) children, more cases with high values of DMFT were identified.

Caries prevalence of study sample according to BMI-age percentiles subgroups are shown in Table 4. A maximum number of caries affected children belonged to the healthy weight $(n=52$, $40.6 \%$ ) and obesity group ( $n=47)$, followed by overweight $(n=27)$, and the least number was underweight $(n=2)$. These differences were statistically significant (Chi-square test, $p<0.003$ ).

The statistical analysis shows a significant difference in OHI-S index between the BMI-age percentiles subgroup. More cases with the high $\mathrm{OHI}-\mathrm{S}$ value were detected among children from the obesity subgroup $(n=7,41.2 \%)(p<0.002)$ (Table 5$)$.

\section{Discussion}

This study has assessed the relationship between BMI-age percentiles and children's oral health. We gained further insight that an inactive way of life, low physical activity, and unhealthy dietary patterns could lead to poor oral hygiene statuses and increase the tendency to develop dental caries and obesity at young ages. ${ }^{2}$

The high prevalence of dental caries in schoolchildren is a serious health concern. The overall dental caries prevalence in our study sample was $47.4 \%(n=128)$. The caries data attained in our study are comparable. It is similar to a study of Yao et al. ${ }^{14}$ where the entire prevalence of dental caries was $44.9 \%$ and with studies conducted in $\mathrm{China}^{15}$ and Spain ${ }^{16}$ where the average prevalence of dental caries was $41.15 \%$. Additionally, in two other studies, one done by Goodarzi et al. ${ }^{17}$ nearly $47 \%$ of children, and another done by Bhayat et al. ${ }^{18} 49 \%$ of children had dental caries. Research 
Table 1: The characteristics of the study population

\begin{tabular}{|c|c|c|c|}
\hline Variable & Frequency $(n)$ & Percentage & $p$ \\
\hline \multicolumn{4}{|l|}{ Sex } \\
\hline Male & 142 & 52.6 & 0.394 \\
\hline Female & 128 & 47.4 & \\
\hline \multicolumn{4}{|l|}{ Age (years) } \\
\hline 12 & 91 & 33.7 & 0.925 \\
\hline 13 & 87 & 32.2 & \\
\hline 14 & 92 & 34.1 & \\
\hline \multicolumn{4}{|l|}{ Income } \\
\hline Low & 43 & 15.9 & $<0.001$ \\
\hline Middle & 146 & 54.1 & \\
\hline High & 81 & 30.0 & \\
\hline \multicolumn{4}{|l|}{ Parental education } \\
\hline Primary school & 49 & 18.1 & $<0.001$ \\
\hline Secondary school & 165 & 61.1 & \\
\hline University & 56 & 20.7 & \\
\hline \multicolumn{4}{|c|}{ Last year visit to the dentist } \\
\hline Yes & 145 & 53.7 & 0.224 \\
\hline No & 125 & 46.3 & \\
\hline \multicolumn{4}{|l|}{ Teeth brushing } \\
\hline Once a day & 132 & 48.9 & 0.715 \\
\hline Twice a day or more & 138 & 51.1 & \\
\hline \multicolumn{4}{|l|}{ Fluorine paste } \\
\hline Yes & 101 & 37.4 & $<0.001$ \\
\hline No & 169 & 62.6 & \\
\hline \multicolumn{4}{|l|}{ Caries } \\
\hline Yes & 128 & 47.4 & 0.394 \\
\hline No & 142 & 52.6 & \\
\hline \multicolumn{4}{|c|}{ Regular physical activity } \\
\hline Yes & 138 & 51.1 & 0.715 \\
\hline No & 132 & 48.9 & \\
\hline \multicolumn{4}{|l|}{ Sweet eating habits } \\
\hline Often & 94 & 34.8 & $<0.001$ \\
\hline Rare & 115 & 42.6 & \\
\hline Sometimes & 61 & 22.6 & \\
\hline \multicolumn{4}{|l|}{ BMI percentile } \\
\hline Underweight & 9 & 3.3 & $<0.001$ \\
\hline Healthy weight & 108 & 40.0 & \\
\hline Overweight & 77 & 28.5 & \\
\hline Obesity & 76 & 28.1 & \\
\hline \multicolumn{4}{|l|}{ DMFT } \\
\hline 0 & 64 & 23.7 & $<0.001$ \\
\hline $1-5$ & 134 & 49.6 & \\
\hline$>5$ & 72 & 26.7 & \\
\hline \multicolumn{4}{|l|}{$\mathrm{OHI}$} \\
\hline 1 & 64 & 23.7 & $<0.001$ \\
\hline 2 & 117 & 43.3 & \\
\hline 3 & 72 & 26.7 & \\
\hline 4 & 17 & 6.3 & \\
\hline
\end{tabular}

$\mathrm{BMI}$, body mass index; $\mathrm{OHI}-\mathrm{S}$, oral health index-simplified The scores of 0 to 1 were classified as low and of 2 to 3 as high oral hygiene index (OHI-S) in Italy ${ }^{19}$ for 12 -year-old children suggests that caries prevalence was $61.6 \%$ that is higher than the levels found in the present study. Moreover, in a study, ${ }^{20}$ the prevalence of dental caries was high, with $84.9 \%$ of the examined children affected. However, according to a different study, ${ }^{21}$ the caries prevalence has turned out even lower (27\%).

In our study, the prevalence of caries was highest among healthy children (40.6\%) and obese children (36.7\%). Risk factors, such as, poor dental hygiene, foods high in sugar, beverages, and reduced saliva production, often promote bacterial growth as well as the manifestation of caries. Equally, in a study, ${ }^{22}$ in public schools, the caries prevalence among the obese group was $50.9 \%$ and among those of normal weight, $52.4 \%$.

Recent studies have shown a high level of dental caries is associated with obese children. ${ }^{23,24}$ Willershausen et al. ${ }^{24}$ showed that 842 elementary schoolchildren, aged 6-11 years, whose weight was normal had significantly fewer caries in their deciduous and permanent teeth than the overweight children. In contrary to our research, the obese children had a lower caries index. ${ }^{25}$ However, a large number of studies have identified that no relationship was found between dental caries and obesity. ${ }^{26-28}$

In the present study, normal-weight children had a significantly higher DMFT value and prevalence of caries compared to the overweight and obese children. A lower DMFT index was detected in the overweight and obese children, compared with children with a healthy weight $(p<0.02)$. This finding is similar in results compared to two previous studies. ${ }^{18,25}$ Likewise, data from the study, ${ }^{29}$ carried out in 2- to 17-year-old participants, identified an inverse association: overweight children had lower levels of dental caries than children in the normal BMI category.

We found that 12-year-old obese children had higher DMFT values, while among those aged 13 and 14 years we did not find a significant difference between DMFT values and BMI subgroups.

Contrary in a few studies, ${ }^{16,30}$ there was no significant correlation between BMI and DMFT in any of the age groups $(6,12$, 15 -year-old $)^{16}$ and no statistical difference in DMFT score between obese and non-obese children, 6-17 years old. ${ }^{30}$

Meanwhile, in our study, the children with normal weight had significantly more dental caries in their permanent teeth, than the overweight and obese children did. This is in opposition with a few certain studies on other groups of children and adolescents, who found that heavier children had more dental caries lesions than those in normal-weight groups. ${ }^{24,31,32}$ Contrary to the present study, an inverse association between caries and BMI was demonstrated. Children with malnutrition were more likely to develop dental caries than those with normal weight or high BMI. ${ }^{15}$ However, the results of other studies did not correlate with BMI categories and the prevalence of dental caries. ${ }^{22}$

This study aimed to examine a possible association between $\mathrm{OHI}-\mathrm{S}$ and BMI-age percentiles subgroups, we report that there was a significant difference in obese children who had higher OHI-S $(p<0.002)$. Likewise, a positive association was found between obesity and oral health status in children, conducted in India. ${ }^{26}$ They have concluded statistically significant $(p<0.01)$ positive correlations between $\mathrm{BMI}$ and $\mathrm{OHI}-\mathrm{S}(r=0.028)$. In relation to the two above studies, the study conveys that the higher value of $\mathrm{OHI}-\mathrm{S}$ in obesity subgroup children could be explained by them adopting low-intensity physical activities together with consuming high-energy value food. ${ }^{33}$ 
Oral Health, Obesity and Physical Activity in Schoolchildren

Table 2: The prevalence of DMFT value in each BMI subgroup based on age

\begin{tabular}{|c|c|c|c|c|c|c|}
\hline Age & $D M F T$ & Underweight, $n$ (\%) & Healthy weight, $n$ (\%) & Overweight n (\%) & Obesity, $n(\%)$ & $p$ \\
\hline \multirow[t]{3}{*}{12 years } & 0 & $3(9.4)$ & $5(15.6)$ & $15(46.9)$ & $9(28.1)$ & 0.003 \\
\hline & $1-5$ & $0(0)$ & $22(50.0)$ & $7(15.9)$ & $15(34.1)$ & \\
\hline & $>5$ & $0(0)$ & $5(33.3)$ & $4(26.7)$ & $6(40.0)$ & \\
\hline \multirow[t]{3}{*}{13 years } & 0 & $1(5.9)$ & $6(35.3)$ & $8(47.1)$ & $2(11.8)$ & 0.217 \\
\hline & $1-5$ & $1(2.2)$ & $18(40.0)$ & $15(33.3)$ & $11(24.4)$ & \\
\hline & $>5$ & $0(0)$ & $12(48.0)$ & $4(16.0)$ & $9(36.0)$ & \\
\hline \multirow[t]{3}{*}{14 years } & 0 & $0(0)$ & $6(40.0)$ & $4(26.7)$ & $5(33.3)$ & 0.382 \\
\hline & $1-5$ & $2(4.4)$ & $20(44.4)$ & $15(33.3)$ & $8(17.8)$ & \\
\hline & $>5$ & $2(6.3)$ & $14(43.8)$ & $5(15.6)$ & $11(34.4)$ & \\
\hline
\end{tabular}

BMI, body mass index

Table 3: The prevalence of DMFT value according to BMI subgroup

\begin{tabular}{llllll}
\hline DMFT & Underweight, $n(\%)$ & Healthy weight, $n(\%)$ & Overweight, $n(\%)$ & Obesity, $n(\%)$ & $p$ \\
\hline 0 & $4(6.3)$ & $17(26.6)$ & $27(42.2)$ & $16(25.0)$ & 0.02 \\
$1-5$ & $3(2.2)$ & $60(44.8)$ & $37(27.6)$ & $34(25.4)$ & \\
$>5$ & $2(2.8)$ & $31(43.1)$ & $13(18.1)$ & $26(36.1)$ & \\
\hline
\end{tabular}

BMI, body mass index

Table 4: The prevalence of dental caries according to BMI subgroup

\begin{tabular}{llllll}
\hline Caries & Underweight, $n(\%)$ & Healthy, weight $n(\%)$ & Overweight, $n(\%)$ & Obesity, $n(\%)$ & $p$ \\
\hline Yes & $2(1.6)$ & $52(40.6)$ & $27(21.1)$ & $47(36.7)$ & 0.003 \\
No & $7(4.9)$ & $56(39.4)$ & $50(35.2)$ & $29(20.4)$ & \\
\hline
\end{tabular}

$\mathrm{BMI}$, body mass index

Table 5: The prevalence of $\mathrm{OHI}$ according to BMI subgroup

\begin{tabular}{|c|c|c|c|c|c|}
\hline $\mathrm{OHI}$ & Underweight, $n$ (\%) & Healthy weight, $n(\%)$ & Overweight, n (\%) & Obesity, n (\%) & $p$ \\
\hline 0 & $4(6.3)$ & $28(43.8)$ & $25(39.1)$ & $7(10.9)$ & 0.002 \\
\hline 1 & $2(1.7)$ & $46(39.3)$ & 39 (33.3) & $30(25.6)$ & \\
\hline 2 & $3(4.2)$ & $29(40.3)$ & $8(11.1)$ & $32(44.4)$ & \\
\hline 3 & $0(0)$ & $5(29.4)$ & $5(29.4)$ & $7(41.2)$ & \\
\hline
\end{tabular}

$\mathrm{BMI}$, body mass index; OHI-S, oral health index-simplified

The scores of 0 to 1 were classified as low and of 2 to 3 as high oral hygiene index $(\mathrm{OHI}-\mathrm{S})$

These findings agree with those of Larsson et al., ${ }^{34}$ who showed that children with higher $\mathrm{OHI}-\mathrm{S}$ values tended to be obese.

A study done in In dia $^{2}$ reported that there is a strong association of lifestyle factors with oral hygiene in pre-adolescent children. A sedentary lifestyle, with more leisure activities, hurts the oral health of children. Another study ${ }^{35}$ shows a high prevalence of dental caries, poor oral hygiene, and increased BMI was associated with television viewing habits of children.

Children and adolescents should do 60 minutes or more of physical activity every day. Most of the 60 minutes should be either moderate or vigorous-intensity aerobic physical activity and should incorporate vigorous-intensity physical activity at least 3 days per week.

Several studies have consistently demonstrated that low levels of parental occupation, lack of education, and household income, as well as reduced dental care, are reflected in poor oral health outcomes in children. ${ }^{20,36,37}$ We have likewise noticed these characteristics among our subjects, significant differences were noticed between the study groups. These differences incorporate income, parental education, fluorine paste, and sugar intake. In a study ${ }^{22}$ conducted in Brazilian adolescents who attend public schools are usually from poor families and present higher levels of dental caries and a greater need for treatment. Dietary intake, particularly that including high sugar, is an established common risk factor for both dental caries and weight gain, ${ }^{14}$ along with socioeconomic status being the second leading factor. ${ }^{28}$

\section{Limitations}

Due to its comparative descriptive design and small sample size, our study was subsequently limited; however, some significant conclusions became apparent. In addition, several variables related to dental caries, such as, oral hygiene and frequency of sugar intake, were controlled for, which expanded the logical limit of the models.

\section{Conclusion}

Bearing in mind that the population of Kosovo, a country characterized by chronically underfunded health services, lacked universal health coverage and insufficient health indicators compared to other countries in the region and throughout Europe, our study results show high dental caries burdens, as well as a difference in outcomes between DMFT and OHI-S 
values among BMI-age percentiles subgroups in schoolchildren. Dentists, pediatricians, and physiatrists should consider the complex relationships between nutrition, physical activity, and oral health by providing the best services to solve these children's health problems. Therefore, it is important to proceed with further research as regards oral health, obesity, and physical activity.

\section{ACKnOWLedgment}

It is a pleasure to thank COL Phillip Hernon, DDS (RET), (US Army, MC) for his valuable suggestions and technical assistance.

\section{References}

1. Mathus-Vliegen EM, Nikkel D, Brand HS. Oral aspects of obesity. Int Dent J 2007;57(4):249-256. DOI: 10.1111/j.1875-595X.2007. tb00128.x.

2. Anand N, Suresh M, Chandrasekaran SC. Effect of obesity and lifestyle on the oral health of pre adolescent children. J Clin Diagnos Res: JCDR 2014;8(2):196. DOI: 10.7860/JCDR/2014/6694.4058.

3. Robinson TN. Television viewing and childhood obesity. Pediatr Clin North Am 2001;48(4):1017-1025. DOI: 10.1016/S0031-3955(05)70354-0.

4. Canning $P$, Courage ML, Frizzell LM, et al. Obesity in a provincial population of Canadian preschool children: differences between 1984 and 1997 birth cohorts. Int J Pediat Obes 2007;2(1):51-57. DOI: 10.1080/17477160601124613.

5. Gunjalli G, Kumar KN, Jain SK, et al. Total salivary anti-oxidant levels, dental development and oral health status in childhood obesity. J Int Oral Health: JIOH 2014;6(4):63.

6. Omar OM, Metwali NE, Elsedfy ZB, et al. Life-style and body mass index, implication for oral health in a group of Egyptian children. Cairo Dent J Part (II) 2007;183:192.

7. Medina-Escobedo M, Villanueva-Jorge S, González-Hoil D, et al. Crystalluria due to calcium oxalate and uric acid, its relationship with $\mathrm{pH}$, calciuria and uricosuria. Biochemistry 2005;30(2):47-52.

8. Kantovitz KR, Pascon FM, Rontani RM, et al. Obesity and dental caries--a systematic review. Oral Health Prev Dent 2006;4(2):137-144.

9. Milgrom $P$, Riedy CA, Weinstein $P$, et al. Dental caries and its relationship to bacterial infection, hypoplasia, diet, and oral hygiene in 6-to 36-month-old children. Commun Dent Oral Epidemiol 2000;28(4):295-306. DOI: 10.1034/j.1600-0528.2000.280408.x.

10. de Anselmo-Peres K, de Magallanes-Bastos J, Dias-de Oliveira Latorre M. Caries severity in children and relationship with social and behavioral aspects. Rev Saúde Pública 2000;34(4):402-408. DOI: 10.1590/S0034-89102000000400014.

11. Centers for Disease Control and Prevention, U.S. Department of Health and Human Services. National Center for Health Statistics Clinical Growth Charts. Atlanta (GA): Centers for Disease Control and Prevention, U.S. Department of Health and Human Services; 2006.

12. World Health Organization. Oral health survey--basic methods. 4th ed., Geneva, Switzerland: WHO; 1997.

13. Simplified Oral Hygiene Index|OHI-S-Oral Health Database, Malmö University, 1964.

14. Yao Y, Ren X, Song X, et al. The relationship between dental caries and obesity among primary school children aged 5 to 14 years. Nutr Hosp 2014;30(1):60-65.

15. Cheng Y, Liao Y, Chen D, et al. Prevalence of dental caries and its association with body mass index among school-age children in Shenzhen, China. BMC Oral Health 2019;19(1):270. DOI: 10.1186/ s12903-019-0950-y.

16. Almerich-Torres T, Bellot-Arcís $C$, Almerich-Silla JM. Relationship between caries, body mass index and social class in Spanish children. Gac Sanit 2017;31(6):499-504. DOI: 10.1016/j.gaceta.2016.09.005.

17. Goodarzi A, Heidarnia A, Tavafian S, et al. Association between dental caries and body mass index-for-age among 10-12-year-old female students in Tehran. Int J Prevent Med 2019;10(1):28. DOI: 10.4103/ ijpvm.IJPVM_528_18.
18. Bhayat A, Ahmad MS, Fadel HT, Association between body mass index, diet and dental caries in Grade 6 boys in Medina, Saudi Arabia.

19. Campus G, Lumbau A, Lai S, et al. Socio-economic and behavioural factors related to caries in twelve-year-old sardinian children. Caries Res 2001;35(6):427-434. DOI: 10.1159/000047486.

20. Köksal E, Tekçiçek M, Yalçın SS, et al. Association between anthropometric measurements and dental caries in Turkish school children. Cent Eur J Public Health 2011;19(3):147. DOI: 10.21101/cejph. a3648.

21. Gupta P, Gupta N, Singh HP. Prevalence of dental caries in relation to body mass index, daily sugar intake, and oral hygiene status in 12-year-old school children in Mathura city: a pilot study. Int J Pediatr 2014;2014:921823. DOI: 10.1155/2014/921823.

22. Moreira PV, Rosenblatt A, Severo AM. Prevalence of dental caries in obese and normal-weight Brazilian adolescents attending state and private schools. Commun Dent Health 2006;23(4):251.

23. Willershausen B, Moschos D, Azrak B, et al. Correlation between oral health and body mass index (BMI) in 2071 primary school pupils. Eur J Med Res 2007;12(7):295.

24. Willershausen B, Haas G, Krummenauer F, et al. Relationship between high weight and caries frequency in German elementary school children. Eur J Med Res 2004;9:400-404.

25. Sánchez-Pérez L, Irigoyen M, Zepeda M. Dental caries, tooth eruption timing and obesity: a longitudinal study in a group of Mexican schoolchildren. Acta Odontol Scand 2010;68(1):57-64. DOI: 10.3109/00016350903449367.

26. Halder $S$, Kaul R, Angrish P, et al. Association between obesity and oral health status in schoolchildren: a survey in five districts of West Bengal, India. Int J Clin Pediat Dentis 2018;11(3):233. DOI: 10.5005/ jp-journals-10005-1517.

27. Pinto A, Kim S, Wadenya $R$, et al. Is there an association between weight and dental caries among pediatric patients in an urban dental school? A correlation study. J Dent Educat 2007;71(11):1435-1440. DOI: 10.1002/j.0022-0337.2007.71.11.tb04414.x.

28. Fernandez MR, Goettems ML, Demarco FF, et al. Is obesity associated to dental caries in Brazilian schoolchildren? Brazil Oral Res 2017;31(0):e83. DOI: 10.1590/1807-3107bor-2017.vol31.0083.

29. Macek MD, Mitola DJ. Exploring the association between overweight and dental caries among US children. Pediat Dentis 2006;28(4):375380.

30. Tripathi S, Kiran K, Kamala BK. Relationship between obesity and dental caries in children-a preliminary study. J Int Oral Health 2010;2(4):65-72.

31. Gerdin EW, Angbratt M, Aronsson K, et al. Dental caries and body mass index by socio-economic status in Swedish children. Commun Dentis Oral Epidemiol 2008;36(5):459-465. DOI: 10.1111/j.16000528.2007.00421.x.

32. Alm A, Fåhraeus C, Wendt LK, et al. Body adiposity status in teenagers and snacking habits in early childhood in relation to approximal caries at 15 years of age. Int J Paediat Dentis 2008;18(3):189-196. DOI: 10.1111/j.1365-263X.2007.00906.x.

33. Feese M, Franklin F, Murdock M, et al. Prevalence of obesity in children in Alabama and Texas participating in social programs. JAMA 2003;289(14):1780-1781. DOI: 10.1001/jama.289.14.1780-b.

34. Larsson B, Johansson I, Weinehall L, et al. Cardiovascular disease risk factors and dental caries in adolescents: effect of a preventive program in Northern Sweden (the Norsjö project). Acta Paediatr 1997;86(1):63-71. DOI: 10.1111/j.1651-2227.1997.tb08834.x.

35. Ravishankar TL, Malik A, Tirth A, et al. Association of dental caries and obesity with television viewing practices among school children of Moradabad city. J Clin Diagn Res 2016;4(124):2376-0311.

36. Auad SM, Waterhouse PJ, Nunn JH, et al. Dental caries and its association with sociodemographics, erosion, and diet in schoolchildren from southeast Brazil. Pediat Dentis 2009;31(3): 229-235.

37. Touger-Decker R, Mobley CC. Position of the american dietetic association: oral health and nutrition. J Am Diete Associat 2007;107(8):1418-1428. DOI: 10.1016/j.jada.2007.06.003. 